\section{Influence of a Vacuum on Electricity}

THE theory of Prof. Edlund that a perfect vacuum is a perfect conductor of electricity, but that a discharge across such a vacuum between two electrodes is prevented by an electromotive force at the surface of the electrode, involves our attributing to the vacuum the property of screening from electrical influence any body which it envelops. If the vacuum be a conductor, what we call induction cannot take place through it.

Not having been able to find any record of an experiment which conclusively proved that a vacuum so perfect as to offer considerable resistance to the passage of a current nevertheless permitted induction to

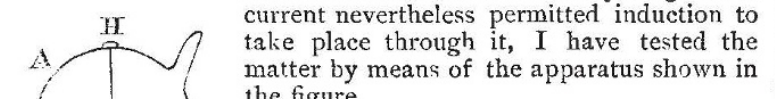
the figure.

$A B$ is a glass tube about $15 \mathrm{~cm}$, long; $\mathrm{C}$ is a light hollow platinum ball, $\mathrm{I} \mathrm{cm}$. in diameter, hung by a fine platinum wire from the top of the tube between $D$ and $\mathrm{E}$ the two separated halves of a cylindrical platinum box, which are insulated from each other and held in positiou by platinum connections sealed into the sides of the tube, and projecting to the outside at $\mathrm{F}$ and $\mathrm{G}$.

It is of importance to mention that the upper terminal $\mathrm{H}$, from which the sphere hung, does not reach more than about 3 G millimetres above the inner surface of the tube. The two halves of the cylindrical box are sufficiently near together to prevent the ball coming in contact with the sides of the glass.

This tuhe was exhansted until an induction current, would give a r2-millimetre spark in air, rather than pass between two terminals, $\mathrm{k}$., sealed in the unper part of the tube with their opposed ends about half a centimetre apart.

A wire about $30 \mathrm{~cm}$. long was then hung from $\mathrm{F}$, and an electrified body presented to the lower end. On the approach of this body to the wire the sphere was at once attracted towards $\mathrm{D}$, and when a discharge was permitted between the electrified object and the wire, the sphere was violently attracted, and a minute spark was seen when the wire holding it touched the cap of the box D. The sphere was then repelled by the similarly charged box.

It thus appears that the phenomena of electric induction take place acro's a discharge-resisting vacuum, and that the sphere hung in it is not screened from electrical influence as it would be if surrounded by a conductor.

Clifton College, Biitol, February 22

\section{The Meteoroid of November 17,1882}

THERE has already been much discussion on this subject, but I do not think that such exceptional phenomena lose any of their interest by having happened a few months ago ; and so I write partly to correct a misapprehension on the part of Mr. Backhouse and Mr. Groneman as to the bearings of the positions of appearance and disappearance of the meteoroid as seen by myself. It seemed to me to appear in the S.E.E. and disappear S.W. by S., but these are not the directions of those points where the trajectory and the horizon would intersect. By mentally continuing the apparent path down to the east and west horizons, points would be reached, nearly, but I think not quite, $180^{\circ}$ apart, the frmer about $20^{\circ} \mathrm{N}$. of $\mathrm{E}$. and the latter nearly opposite, so that I scarcely think that it was a great circle, but it is very tncertain. Mr. Saxby states that a similar cloud was observed to cross the zenith of Brussels by M. Montigny. Now there are two accounts-one by M. Zeeman of Ziericksee and the other from near Rye (Sussex) - which seem to consistently apply to one and the same thing, for the latter place is W. by $20^{\circ} \mathrm{S}$. from Ziericksee, and from both places the same elevation of about $50^{\circ}$ was reached. 'These accounts, if combined with that from Brussels, indicate a height of about 70 miles; but then how does such a height agree with some of the English observations? On the supposition of the above height, the altitudes of culmination as seen from Woodbridge and
Windsor would be about $29^{\circ}$, from Bristol $25^{\circ}$, and from York $10^{\circ}$ only, which last angle is directly at variance with the actual one. For my part, I will give up the reconciling of such contradictory evidence to those who have an aptitude for conundrums. The evidence is in favour of this being an auroral manifestation, but the spectrum of the cloud does not prove this, for as yet it is not known whether the extremely rarefied uppe atmosphere may not be excited to such incandescence as will yield the so-called "auroral" spectrum by other means than the electric discharge, as, for instance, by the passage of a cloud of meteorites. Mr. Petrie upholds the latter hypothesis, but I think that there is a simple but weighty objection to it ; for it is difficult to see how a cloud of meteoric dust of such closeness and defined form as the appearance of this cloud would imply, could travel through space for any length of time without coalescing into one granular lump, owing to the mutual gravitation of its particles. Of course this objection will have the less weight the smaller we suppose the individual particles to be. This argument will scarcely apply to the well-known meteor streams, whose individual particles are really so very far apart. If this "flying arch" was subject to gravity, it certainly had more than sufficient velocity to prevent it being appropriated by our earth as a satellite, for the tangential speed necessary to a circular orbit of 4100 miles radius round our earth would only be about $4 \frac{3}{4}$ miles per second, with a period of $I_{2}^{\frac{1}{2}}$ hours. All interested in this phenomenon will no doubt pay more attention to the southern sky during future aurorac, in hopes of noting something more of a similar nature, and they will also look forward to seeing a full account of Prof. Lemström's remarkable experiments on the nature of the aurora, which he has been conducting at Sodankylä with such unlooked-for results.

Heworth Green, York

\section{H. Dennis Taylor}

\section{A Meteor}

LAST evening at 9.35 p.m. a remarkably large and brilliant meteor was seen from here, appearing at a point about $10^{\circ}$ east of $\eta$ Canis Majoris, passing slowly over that star in a south-west direction, and vanishing a few degrees above the horizon; time about three seconds. Its ligbt had a pale green tint, and in brightness and apparent diameter it far exceeded Sirius (which was particularly bright all the evening), so much so that my companions, though not looking in that direction, were instantly attracted by the light, and saw it in its splendour.

R. W. S. GRIFFITH

Eyeworth Lodge, Lyndhurst, Hants, March 3

\section{Aurora}

LAST night at about ten o'clock there were two beautiful white auroral streamers, like the tails of enormous comets, near the Pleiades. They were nearly vertical, and slowly moved, in a direction parallel to the horizon, towards Orion, after which they gradually vanisbed. 'I here was little wind, and the night was bright starlight, after a cloudy day. There was an auroral glow like twilight over the northern horizon. The barometer rose during yesterday and last night, and stands high.

Old Forge, Dunmurry, Co. Antrim, February 28

\section{Hovering of Birds}

WITH regard to $\mathrm{Mr}$. W. Clement Ley's remarks, I have already been permitted to explain in NATURE (vol. xxvii. p. 366) how I had accidentally misunderstood Mr. Airy's meaning. I do not believe that any bird having a greater specific gravity than the air can retain a perfectly fixed position in a calm without some wing-motion. Mr. Ley "believes that there is nothing in the etymology of the word 'hover' that implies movement." This has induced me to look up a somewhat voluminous and recent dictionary, in which I find "Hover, vi. i. (W. hoviaw, to hang over, to fluctuate, to hover). To flap the wings, fluttering or fiapping the wings with short irregular flights"; and more to the same effect, all indicating movement. J. RAE

\section{AMATEURS AND ASTRONOMICAL. OBSERVATION}

THE labour done by astronomical anateurs has had no little influence upon the progress of the science. The work achieved by them has indeed often been of the 